\title{
REPRESENTASI NASIONALISME DALAM FILM ANIMASI BATTLE OF SURABAYA
}

\author{
Ukon Furkon Sukanda, S.Sos, M.Ikom \\ Siti Setyawati Yulandari \\ Email: ufsukanda@unis.ac.id \\ Prodi Ilmu Komunikasi, FISIP Universitas Islam Syekh Yusuf Tangerang
}

\begin{abstract}
ABSTRAK
Representasi Nasionalisme Dalam Film Battle of Surabaya merupakan tema dalam penelitian ini. Masalah yang ditengahkan adalah bagaimana film Battle of Surabaya menggambarkan Nasionalisme, Perasahabatan, dan Motivasi Diri melalui tanda icon,index, dan symbol berdasarkan analisis model triadic Charles Sanders Pierce. Bagaimana Nasionalisme, Persahabatan, dan Motivasi Diri direpresentasikan dalam film Battle of Surabaya. Penelitian ini menggunakan pendekatan kualitatif dan paradigma yang digunakan ialah paradigma konstruktivisme. Adapun metode penelitian yang digunakan adalah analisis semiotika model Charles Sanders Pierce.

Teori yang digunakan dalam penelitian ini ialah representasi Stuart Hall dan semiotika model Charles Sanders Pierce. Menurut Stuart Hall representasi bekerja melalui sistem representasi.Sistem representasi ini terdiri dari dua komponen penting, yakni konsep dalam pikiran dan bahasa. Hasil penelitian ini menampilkan beberapa tanda dan reperesentasi yang muncul dalam scene-scene pada film tersebut. Penulis mendapatkan data yang ditinjau dari konsep trikotomi object yakni Icon, Index, dan Symbol milik Charles Sanders Pierce. Tanda Icon, Index dan Symbol menggambarkan adanya benda, ekspresi, maupun tindakan yang menejelaskan bagaimana suatu scene dapat menjadi suatu tanda adanya nilai Nasionalisme, Persahabatan dan Motivasi Diri.

Kata kunci: Representasi, Semiotika, Nasionalisme, Persahabatan, Motivasi Diri, Film, Battle of Surabaya.
\end{abstract}

\section{ABSTRACT}

Representation of Nationalism in the film Battle of Surabaya is the theme of this study. The problem that being addressed is, how does the film Battle of Surabaya depict Nationalism, Friendship, and Self-Motivation through icon, index, and symbol signs based on the analysis of Charles Sanders Pierce's triadic model. How is Nationalism, Friendship, and SelfMotivation represented in the film Battle of Surabaya. This study uses a qualitative approach and the paradigm that being used is the constructivism paradigm. The research method that used is the semiotics analysis of Charles Sanders Pierce's model.

The theory that used in this study is the representation of Stuart Hall and Charles Sanders Pierce's semiotics. According to Stuart Hall, representation works through a representation system. This representation system consists of two important components, namely concepts in mind and language.

The author gets the data in terms of the concept of trichotomy objects namely Icon, Index, and Symbol of Charles Sanders Pierce. Icon, Index and Symbol signs depict objects, expressions, and actions that explain how a scene can be a sign of the value of nationalism, friendship and self-motivation.

KeyWords: Representation, Semiotics, Nationalism, Friendship,Self-Motivation, Film, Battle of Surabaya 


\section{PENDAHULUAN}

Turner mengungkapkan bahwa "film bukan hanya sekedar refleksi dari realitas dari kehidupan masyarakat melainkan banyak pesan yang terkandung dalam adegan film sekaligus representasi dari kehidupan masyarakat yang sekedar "memindah" realitas ke layar tanpa mengubah realitas aslinya". Pesan yang disampaikan dalam film pun disampaikan dalam bentuk lambang komunikasi. Lambang sebagai media primer dalam proses komunikasi adalah bahasa, sikap (gesture), isyarat, gambar, warna dan simbol lainnya yang secara tidak langsung mampu menerjemahkan pikiran dan perasaan komunikator kepada komunikan(Sobur, 2017, p. 28).

Film-film Indonesia sendiri selama dua dekade ini (1980-an dan 1990-an) terpuruk sangat dalam. Insan film Indonesia seperti tak bisa berkutik menghadapi arus film impor. "Di awal millenium baru ini tampaknya mulai ada gairah baru dalam industri film Indonesia. Dengan genre film yang bervariasi itulah yang memberikan kesempatan media film menjadi sarana pembelajaran dan motivator bagi
masyarakat(Sutadi).Dimana salah satunya adalah film animasi pertama karya anak bangsa yang mengangkat genre nasionalisme dengan judul Battle of Surabaya.

Terlebih lagi film Battle of Surabaya ini merupakan adaptasi yang mengambil latar belakang pertempuran pada tanggal 10 November 1945 di Surabaya.Namun tokoh yang diciptakan dalam film ini adalah fiksi. Karena tokoh utama yang digambarkan adalah seorang anak kecil bukan seorang tokoh pahlawan negara. Menurut Suryanto sang sutradara, "film ini mengangkat cerita bahwa semua orang bisa menjadi pahlawan dengan caranya sendiri. Lantaran hal itu, tokoh dalam film bukan pahlawan super. Tokoh diceritakan mengalami proses menjadi pahlawan yang bisa ditiru dalam kehidupan nyata” (Mustafa).

Nasionalisme yang utuh adalah "ide dan cita-cita tentang masa depan bagaimana karakter sebuah bangsa yang merdeka kukuh di tengah arus globalisasi. Karena itu, nasionalisme lama harus direkonstruksi menjadi nasionalisme baru yang berpijak pada tantangan-tantangan kebangsaan yang makin kompleks" (Tempo). 
Saat ini film diproduksi bukan hanya memberikan cerita yang dapat menghibur penonton semata, tetapi juga diproduksi sebagai media penyampaian pesan kepada khalayak luas melalui salah satu instrumen media massa. Dan pesan yang disampaikan pun bervariatif sesuai dengan genre film yang diproduksi. Mulai dari biografi, drama, science fiction, romance, animation, adventure dsb. Semua dapat memberikan pesan sosial kehidupan bagi khalayak yang menontonnya. Film juga dapat menginspirasi penonton dengan adanya jalan cerita yang bagus, karakter yang kuat, sinematografi yang menarik dan juga penghargaan yang diterima atas film tersebut.

$\begin{array}{lrr}\text { Georg } & \text { Gerbner memberi } \\ \text { pengertian } & \text { "komunikasi } & \text { massa }\end{array}$
dengan singkat, yaitu produksi dan distribusi yang berlandaskan teknologi dan lembaga dari arus pesan yang berkelanjutan serta paling luas dimiliki orang dalam masyarkat industry" (Suryanto, 2015, p. 145).

"Salah satu saluran media massa modern adalah film. Karena film merupakan salah satu bentuk karya seni yang menjadi fenomena dalam masyarakat saat ini. Film merupakan salah satu sarana hiburan yang mempunyai daya tarik yang cukup tinggi dalam berbagai kalangan masyarakat, dari ekonomi menengah sampai ekonomi atas, dari anak-anak hingga dewasa" (Mambor, 2000, p. $1)$.

"Film mempunyai dampak tertentu bagi penontonnya, dalam banyak penelitian tentang dampak film terhadap masyarakat, hubungan antara film dan masyarakat selalu secara linier. Artinya film, baik yang ditayangkan di televisi maupun bioskop, selalu memengaruhi dan membentuk masyarakat berdasarkan muatan pesan (message) di baliknya, tanpa berlaku sebaliknya. Selain itu, kekuatan dan kemampuan film menjangkau banyak segmen sosial, lantas membuat para ahli film memiliki potensi untuk memengaruhi khalayaknya" (Ahandi).

Untuk memahami pesan yang disajikan dalam film, saat ini bidang kajian yang tepat untuk membaca makna dalam film adalah analisis struktural atau semiotika, dimana film dibangun oleh banyak tanda yang bekerja sama dengan baik untuk mencapai efek yang diharapkan. 
Charles Sanders Pierce mendefinisikan "semiotika sebagai studi tentang tanda dan segala sesutu yang berhubungan dengannya, yakni cara berfungsinya, hubungan dengan tanda-tanda lain, pengirimannya, dan penerimannya oleh mereka yang mempergunakannya" (Vera, 2014, p. 12).

"Sistem tanda yang sangat kompleks bisa ditemukan pada film yang merupakan cerminan sekaligus kreasi budaya yang merepresentase bentuk realitas di masyarakat. Karena itu, dalam perkembangannya film tidak lagi dimaknai sebagai karya seni semata. Akan tetapi lebih sebagai praktik sosial kombinasi antara realitas dan rekonstruksi” (Ichsani).

Melalui analisis struktural atau semiotika ini nantinya yang akan bekerja dalam membaca makna atau pesan yang berkaitan dengan penelitian, dalam sebuah film animasi 2D dengan judul Battle of Surabaya. Ketertarikan penulis dalam meneliti film ini adalah karena melihat fenomena bangsa yang saat ini hampir tergilas oleh globalisasi yang mendunia, dimana sudah hampir tidak ada lagi terlihat jiwa nasionalisme dalam menjaga integritas bangsanya.
Bisa dilihat kebanyakan pemuda-pemudi Indonesia saat ini lebih banyak menggandrungi gaya kehidupan negara lain. Gaya hidup Korean Wave yang saat ini membumi di Indonesia, menjadikan masyarakat lupa akan wujud asli bangsanya sendiri. Selain itu kebanyakan masyarakat Indonesia lebih memilih pergi keluar negeri sebagai tujuan wisatanya, padahal lebih dari itu banyak sekali objek wisata Indonesia yang tak kalah menarik dibandingkan negara luar. Itulah berbagai tanda yang menandakan berkurangnya rasa nasionalisme dikalangan rakyat bangsa Indonesia. Yang semestinya dapat dibangkitkan dengan hal-hal sederhana seperti menerapkan kehidupan kita dengan tokoh utama dalam film Battle of Surabaya yang dengan tidak sengaja dan juga secara sederhana mampu berkontribusi demi Indonesia yang lebih baik.

\section{LANDASAN KONSEPTUAL}

\section{Representasi}

Menurut Stuart Hall dalam bukunya Representation: "Cultural Representation and signifying practices, "Representation connects meaning and language to culture... 
Representation is a essential part of the process by which meaning is produced and exchangedbetween member of culture". "Melalui representasi, suatu makna diproduksi dan dipertukarkan antara anggota masyarakat. Jadi dapat dikatakan bahwa, representasi secara singkat adalah satu cara untuk memproduksi makna" (Hall, 1997).

Menurut Stuart Hall "berpikir dan merasa juga merupakan sistem representasi. Sebagai sistem representasi berarti berfikir dan merasa juga berfungsi untuk memaknai sesuatu. Oleh karena itu, untuk dapat melakukan hal tersebut, diperlukan latar belakang pemahaman yang sama terhadap konsep, gambar, dan ide (culture codes)" (Hall, 1997).

\section{Nasionalisme}

"Nasionalisme adalah satu paham yang berpendapat bahwa kesetiaan tertinggi individu harus diserahkan kepada kebangsaan" (Kohn, 1984, p. 11). Perasaan sangat mendalam akan suatu ikatan yang erat dengan tanah tumpah darahnya, dengan tradisi-tradisi setempat dan penguasa-penguasa resmi di daerahnya yang selalu ada di sepanjang sejarah dengan kekuatan yang berbeda-beda.

"nasionalisme diartikan sebagai paham atau ajaran untuk mencintai bangsa dan negara sendiri. Jadi secara garis besar nasionalisme adalah sebuah paham atau ajaran mengenai cinta dan kesetiaan terhadap bangsa negara" (Budiman, 2006, p. 16).

\section{Film}

"Film adalah media komunikasi massa kedua yang muncul di dunia setelah surat kabar mempunyai masa pertumbuhan pada akhir abad ke-19. Pada awal perkembangannya, film tidak seperti surat kabar yang mengalami unsurunsur teknik, politik, ekonomi, sosial, dan demografi yang merintangi kemajuan surat kabar pada massa pertumbuhan pada abad ke-18 dan permulaan abad ke-19. Film dianggap lebih sebagai media hiburan ketimbang media pembujuk. Film sebenarnya punya kekuatan bujukan atau persuasi yang besar. Kritik publik dan adanya lembaga sensor juga menunjukkan bahwa sebenarnya film sangat berpengaruh. Adanya film 
membuat kita mengenal dunia yang berbeda dan memberi warna baru sebuah hiburan untuk semua khalayak umum segala usia" (Mambor, 2000, p. 1)

\section{Persahabatan}

"Definisi pesahabatan adalah hubungan personal berdasarkan kesukarelaan yang memberikan keintiman serta bantuan dimana orang yang bersahabat tersebut meminta untuk menjadi teman" (Adams)

\section{Motivasi Diri}

"Menurut McClelland, motivasi adalah manakala kebutuhan seseorang terasa sangat mendesak, maka kebutuhan akan memotivasi dan berusaha keras memenuhi kebutuhan tersebut muncul" (Teori Motivasi McClelland, 2011).

\section{METODE PENELITIAN}

Metode penelitian yang digunakan adalah penelitian deskriptif - kualiatif yang menggunakan analisis semiotika Charles Sanders Pierce.

$\begin{array}{rrr}\text { Tujuan } & \text { dari } & \text { deskriptif- } \\ \text { kualitatif } & \text { adalah } & \text { untuk }\end{array}$

menggambarkan suatu fenomena atau gejala sosial dengan jalan menggambarkan atau melukiskan secara sistematis, akurat dan factual mengenai fakta-fakta keadaan subjek atau objek penelitian. Ciri-ciri pada metode deskriptif yaitu metode penelitian dilakukan untuk membuat gambaran mengenai situasi atau kejadian (Pujileksono, 2015, p. 21).

Orientasi penelitian ini selanjutnya akan menggambarkan makna film Battle of Surabaya. Dalam hal ini peneliti menggunakan metode penelitian deskriptif-kualitatif dengan analisis semiotika sebagai dasar penelitian. Dengan pertimbangan bahwa semiotika melihat media (film) sebagai struktur keseluruhan, berupaya mencari makna yang laten dan kontatif.

Paradigma yang digunakan dalam penelitian ini adalah paradigma konstruktivisme. Sebuah paradigma yang memandang segala sesuatu adalah hasil konstuksi sosial. Aliran ini menyatakan bahwa realitas itu berada dalam beragam bentuk konstruksi mental yang didasarkan 
pada pengalaman sosial, berifat lokal, dan spesifik (Salim, 2006, p. 71).

Paradigma konstruktivisme berbasis pada pemikiran umun tentang teori-teori yang dihasilkan oleh peneliti dan teoritis aliran konstruktivisme. Little john mengatakan bahwa "teori-teori aliran konstruktivis berlandaskan pada ide bahwa realitas bukanlah bentuk objektif, tetapi dikonstruktruksikan melalui proses interaksi dalam kelompok, masyarakat, dan budaya (Wibowo, 2011, p. 136).

Tradisi yang digunakan dalam penelitian ini menggunakan pendekatan analisis semiotika Charles Sanders Pierce sebagai upaya untuk mengembangkan pemahaman atas objek yang diteliti. Tradisi penelitian yang digunakan dalam analisis semiotika adalah interpretatif.

Objek dalam penelitian ini adalah scene-scene yang ada didalam flm Battle of Surabaya (2015) karya Ariyanto Yuniawan. Dimana dalam scene tersebut peneliti akan mencari representasi mengenai nilai-nilai nasionalisme, persahabatan dan motivasi diri. Melalui adegan-adegan gambar dan percakapan yang terkandung di dalam film berduarsi 1 jam 39 menit tersebut.

Peneliti membutuhkan waktu untuk melakukan penelitian ini sekitar 6 (enam) bulan, terhitung sejak bulan Maret 2019 sampai dengan bulan Agustus 2019.

Penelitian ini menggunakan metode semiotika model triadic yang digunakan Charles Sanders Pierce. Gagasan Pierce bersifat menyeluruh, deskripsi struktural dari semua sistem penandaan. Ia ingin mengidentifikasi partikel dasar dari tanda dan menggabungkan kembali semua komponen dalam struktur tunggal (Kriyantono, 2006, p. 91).

\section{HASIL PENELITIAN}

Representasi nasionalisme yang muncul dalam film Battle of Surabaya setelah penelitian ini menggunakan peta tanda Pierce yakni Ikon, Indeks, dan symbol, adalah:

1. Sikap siap berperang merepresentasikan bahwa pada masa perperangan seluruh masyarakat, maupun remaja yang tergabung dalam 
PETA (Pembela Tanah Air) memiliki jiwa patriotisme.

2. Peristiwa bersejarah (perobekan bendera Belanda) merepresentasikan bahwa setiap perilaku yang dilakukan untuk membela negara pada masa peperangan adalah sebuah peristiwa yang akan menjadi sejarah.

3. Aksi turun kejalan merepresentasikan cara menyebarkan informasi kepada masyarakat pada masa peperangan. Kegiatan itu dilakakukan juga guna sebagai media menyemangati warga agar berani melawan siapa pun yang ingin kembali datang menjajah.

4. Tertanaman rasa cinta tanah air merepresentasikan bahwa pada masa pereperangan tokoh Musa memiliki rasa ingin membela tanah air, agar kemerdekaan bisa terealisasi dengan kekal.

5. Tugas tentara merepresentasikan kewajiban melindungi negara yang harus dilakukan oleh para tenaga militer dengan sungguh- sungguh agar terciptanya kedamaian negara yang utuh.

6. Menghargai nyawa orang lain merepresentasikan tokoh Musa yang memiliki jiwa humanity yang tinggi. Memberi pertolongan kepada kapten John Wright yang dalam kondisi lemah.

7. Situasi dalam perang merepresentasikan penggambaran dampak suatu wilayah yang diakibatkan oleh perperangan.

8. Jiwa rela berkorban merepresentasikan bahwa tokoh Danu memiliki jiwa patriotisme, yang rela mengorbankan nyawanya demi melindungi temannya Musa.

9. Pesan perdamaian merepresentasikan hikmah yang dapat diambil dari setiap perperang yang dilakukan. Bahwa setelah perperangan usai mengajarkan perdamaian antar pelaku negara yang melakukan perang.

Representasi persahabatan yang muncul dalam film Battle of Surabaya setelah 
penelitian ini menggunakan peta tanda Pierce yakni Ikon, Indeks, dan symbol, adalah:

1. Saling memberi merepresentasikan bahwa dalam berteman saling berbagai makanan ataupun memberikan hal lainnya adalah sesuatu yang lumrah dalam pertemanan.

2. Saling mensupport merepresentasikan bahwa kegiatan saling mendukung apa yang dilakukan teman adalah tanda bahwa kita penduli terhadap apa yang dilakukan oleh teman kita.

3. Melakukan hal bahagia bersama merepresentasikan bahwa kegiatan yang membahagian biasa dilakukan bersama teman.

4. Saling menolong merepresentasikan bahwa dalam berteman tidak mengenal kata balas budi ataupun mengharapkan belas kasih. Karena kegiatan saling menolong dilakukan tanpa pamrih dalam berteman.

5. Rela mempertaruhkan nyawa merepresentasikan bahwa dalam persahabatan bahkan hingga merelakan nyawa diri sendiri, untuk melindungi sahabat yang ada dalam bahaya.

6. Menjaga pemberian merepresentasikan bahwa ketika seorang sahabat memberikan barang berharganya kepada temannya, itu berarti tandanya harus disimpan dengan baik. Dan sahabat yang memberikan berarti telah benar-benar mempercayai temannya, sehingga ia mempercayai barang berharganya kepada temannya untuk dijaga dengan baik.

Representasi motivasi diri yang muncul dalam film Battle of Surabaya setelah penelitian ini menggunakan peta tanda Pierce yakni Ikon, Indeks, dan symbol, adalah:

1. Merelakan yang telah pergi merepresentasikan bahwa tokoh Musa memiliki sifat tegar karena ia merelakan kepergian Mr. Yoshimura yang meninggal dihadapanya. 
2. Merawat orang tua merepresentasikan bahwa tokoh Musa memiliki sifat berbakti kepada orang tua, karena ia bertanggungjawab penuh untuk menghidupi dan mengurus Ibunya yang sedang sakit.

3. Belajar bela diri sejak kecil merepresentasikan bahwa tokoh Yumna memiliki ketertarikan akan dunia bela diri sejak ia usia dini.

4. Belajar hal baru merepresentasikan bahwa tokoh Musa memiliki semangat belajar yang tinggi. Karena dia selalu bersemangat dalam mempelajari hal baru dalam hidupnya.

5. Tidak mudah menyerah merepresentasikan bahwa tokoh Yumna memiliki sifat gigih saat belajar. Ketika kegagalan menghampirinya, ia akan berusaha untuk terus belajar menjadi lebih baik.

6. Berani mengambil tindakan besar merepresentasikan bahwa tokoh Musa tidak takut mengambil keputusan yang bahkan dapat mengancam 
berkembang pesat setelah

keluar dari organisasi tersebut.

10. Amanah merepresentasikan bahwa tokoh Danu memiliki sifat yang bersungguhsungguh dalam menjalankan setiap pesan yang diberikan orang terhadapnya. Ia gigih dalam menjalankan setiap amanat yang sudah menjadi tugasnya.

11. Menghadapi tantangan merepresentasikan bahwa tokoh Musa memiliki sifat yang tidak takut akan rintangan yang harus ia hadapi. Ia tidak mundur ketika dihadapkan pada situasi yang menantangnya untuk melakukan hal ekstrim.

\section{KESIMPULAN}

Berdasarkan hasil deskripsi dari Bab IV mengenai analisis semiotika Charles Sanders Pierce tentang representasi nasionalisme dalam film animasi Battle of Surabaya. Penelitian ini mengambil kesimpulan atas tanda yang muncul dan representasi dari tiga nilai sosial yakni nilai nasionalisme, nilai persahabatan, dan nilai motivasi diri sebagai berikut:

Nilai nasionalisme digambarkan dengan munculnya ikon penggambaran situasi perperangan, penggunaan senjata api dan bambu runcing, pakaian berseragam, bendera, pesawat tempur. Indeks yang ditampilkan banyak menggambarkan sikap pemberani, pemberontakan, dan humanity. Kemudian symbol yang ditonjolkan adalah sifat cinta tanah air, bela negara, dan juga patriotisme. Representasi nasionalisme dalam film iniberupa perjuangan Indonesia dalam melawan penjajahan kolonial Belanda dan kipas hitam, pada masa perang dunia ke II di Surabaya.

Nilai persahabatan digambarkan dengan munculnya ikon berupa sifat berbagai makanan, ekspresi wajah yang sedih maupun ceria, bahumembahu. Indeks yang ditampilkan semua tindakan dilakukan bersama sahabat. Kemudian yang symbol 
ditonjolkan adalah sifat tulus yang dilakukan antar sahabat. Sehingga representasi persahabatan dalam film ini secara garis besar adalah cara tokoh Musa, Yumna dan Danu berteman. Mereka saling menjaga hubungan pertemanan hingga maut yang memisahkan.

Nilai motivasi diri digambarkan dengan munculnya ikon dengan ekspresi kesedihan, ketulusan, keberanian, dan kepercayadirian. Indeks yang ditampilkan segala perilaku yang dilakukan dengan landasan pantang menyerah, balas dendam, tidak berlarut-larut dalam kesedihan, dan tekad kuat. Kemudian symbol yang ditonjolkan adalah sifat kegigihan dari tiap-tiap tokoh untuk mewujudkan keinginannya. Maka dapat disimpulkan representasi motivasi diri dalam film ini adalah, segala tindakan yang dilakukan karena adanya sentuhan emosional. Yang membuat setiap tokoh dalam film ini berpikir dan bertindak.

\section{DAFTAR PUSTAKA}

Adams, dkk, Definition of frienship in the thrid age : age, gender, and study location effect, Journal of aging studies. Vol 14 No.1, hlm. 117-133

Affan Ahandi, "Representasi nasionalisme dalam film The Lady", http//:www.cinarharapan.co.id/hibur an/budaya/2002/03/04/bud02.html, cinarharapan.co.id, diakses 24 Juni 2019 pukul 10:54

Budiman, Arief. 2006. Kebebasan, Negara, Pembangunan. Jakarta: Pustaka Alvabet

Hall, Stuart. 1997. The Work of Representation. Representation and Signifying Prectices. Ed. Stuart Hall

Ichsani, Nurul. Antara Tirani, Demokrasi dan Perempuan, Jurnal Komunikasi KAREBA, Vol. 5 No.1

Insan Pelajar, “Teori Motivasi McClelland", https://henny2011.wordpress.com/201 1/04/05/teori-motivasi-mcclelland/, diakses 14 September 2019 pukul $6: 23$

Kadi, Saurip. 2008. Mengutakamakan Rakyat. Jakarta: Yayasan Obor Indonesia

Kohn, Hans. 1984. Nasionalisme, Arti, dan Sejarahnya, Jakarta: PT. Pembangunan 
Kriyantono, Rachmat. 2006. Teknik

Praktis Riset Komunikasi. Jakarta: Kencana

Victor. C. Mambor. 2000. Satu Abad

Gambar Idoep di Indonesia. Jakarta:

Sinematek Indonesia

Aditya Mustafa, "Sejauh Mana

Campur Tangan Disney di 'Battle of Surabaya' ?”, https://www.cnnindonesia.com/hibura n/20150818200829-220-

73002/sejauh-mana-campur-tangandisney-di-battle-of-surabaya, diakses 28 Juni 2019 pukul 10:45

Pujileksono, Sugeng. 2015. Metode Penelitian Komunikasi Kualitatif. Malang: Intrans Publising

Salim, Agus. 2006. Teori dan Paradigma Penelitian Sosial. Yogyakarta:Tiara Wacana

Sobur, Alex. 2017. Semiotika Komunikasi. Bandung: Cetakan Kelima PT Remaja Rosdakarya

Sumarno, Marselli. 1995. Suatu Sketsa Perfilman Indonesia Jakarta:
Lembaga Studi Film bekerjasama dengan Pimpinan Pusat Pemuda Panca Marga

Suryanto. 2015. Pengantar Ilmu Komunikasi. Bandung: CV Pustaka Setia

Heru Sutadi, "Sejarah Film dan Perkembangan Film Indonesia”, https://www.kompasiana.com/herusut adi/54ff8c3da33311f44d5104db/sejar ah-film-dan-perkembangan-filmindonesia, diakses 25 Juni 2019 pukul $3: 57$

Tempo.co, "Rekrontruksi Nasionalisme Kaum Muda", 16 November 2007, Tempo.co, diakses 25 Juni 2019 pukul 10:51

Vera, Nawiroh. 2014. Semiotika dalam Riset Komunikasi. Bogor: Ghali Indonesia

Wibowo, Indriawan. 2011. Semiotika Komunikasi. Jakarta: Mitra Wacana Media. 